\title{
Endovascular stents in the management of coarctation of the aorta in the adolescent and adult: one year follow up
}

\author{
D A Harrison, P R McLaughlin, C Lazzam, M Connelly, L N Benson
}

\begin{abstract}
Objectives-To test the hypothesis that endovascular stents used with dilation of coarctation of the aorta $(\mathrm{CoA})$ improve late outcomes. Balloon dilation for CoA has been limited by concerns over the risk for acute dissection, late restenosis, or aneurysm formation.

Design-All patients seen with CoA between November 1994 and September 1997 underwent attempted stent implantation. Follow up was obtained for all patients and a subgroup $(\mathrm{n}=18)$ had repeat catheterisation at a mean (SD) of $1.3(0.5)$ years to assess residual gradient and stentCoA morphology.

Results-Stents were placed in 27 patients (15 male and 12 female patients, mean age 30.1 (13.1) years), of whom seven had prior surgical coarctectomy and one had a prior balloon dilation. Hypertension was present in 26 patients (mean pressure 164 (26)/86 (13) $\mathrm{mm} \mathrm{Hg}$ ), of whom 16 were on antihypertension drugs. CoA gradients were 46 (20) $\mathrm{mm} \mathrm{Hg}$ (range 18-106 $\mathrm{mm} \mathrm{Hg}$ ) at baseline and $3(5) \mathrm{mm} \mathrm{Hg}$ after the procedure. One patient had a stroke following the procedure; another patient had incomplete dilation and underwent a second procedure. At 1.8 (1) years after the procedure the mean pressure was $130(14) / 74(11) \mathrm{mm} \mathrm{Hg}$ with seven patients on antihypertension treatment. The clinical gradient was 4 (8) $\mathrm{mm} \mathrm{Hg}$ (range $0-32 \mathrm{~mm} \mathrm{Hg}$ ). At follow up angiography, the mean gradient was $4(6) \mathrm{mm} \mathrm{Hg}$, and two patients had a gradient over $10 \mathrm{~mm} \mathrm{Hg}$. Aneurysms formed in three patients at the dilation site; one patient was referred for surgery.

Conclusion-In this age group stent management for CoA appears to be an effective technique and results in sustained reduction in CoA gradients at early term follow up, but aortic aneurysm was detected in $17 \%$ of patients who had repeat angiography.

(Heart 2001;85:561-566)
\end{abstract}

Keywords: angioplasty; coarctation of the aorta; congenital heart defects; stents

Surgical correction of coarctation of the aorta (CoA) improves a patient's natural history and assists in control of hypertension. ${ }^{1}$ Residual problems of recurrent CoA include need for reoperation, persistent hypertension, and the uncertain significance of exercise induced hypertension. ${ }^{1-6}$

Over the past two decades non-surgical

Department of Medicine, Divisions of Cardiology, The Toronto Hospital and The Hospital for Sick Children, University of Toronto School of Medicine, 555

University Avenue, Toronto, Ontario M5G 1X8, Canada

D A Harrison P R McLaughlin C Lazzam

M Connelly

Department of Pediatrics, The Toronto Hospital and The Hospital for Sick Children

L N Benson

Correspondence to: Dr Benson benson@sickkids.on.ca

Accepted 9 January 2001 angioplasty ${ }^{7-25}$ Although initial proce success has been well documented, balloon management has been complicated by aortic dissection, ${ }^{13} 202123$ cerebrovascular accidents, ${ }^{1518}$ incomplete relief of the CoA gradient, ${ }^{811-15} 2324$ and aneurysm formation. ${ }^{9-15} 192326$ Perhaps the most limiting feature of CoA angioplasty is significant residual gradient $(>20 \mathrm{~mm} \mathrm{Hg}$ ) at late follow up in $7-36 \%$ of patients. . $^{810-151727}$ Residual gradient has been attributed to an incomplete immediate result, recurrent stenosis, ${ }^{11}$ and associated transverse arch hypoplasia.

Endovascular stents have been applied in the management of $\mathrm{CoA}$ as an alternative to balloon dilation alone. ${ }^{16}{ }^{28-35}$ Stent use has been limited by the maximal diameters that can be achieved without inducing strut fatigue; follow up of their use has been of limited duration. Recently, larger stents have become available (Johnson \& Johnson Interventional, Warren, New Jersey, USA), which can be expanded to
$25 \mathrm{~mm}$ in diameter, well within the arch diameter of an adult aorta. We hypothesised that the use of such implants would reduce the development of restenosis, would not compromise vascular wall integrity, and would avoid the need for reintervention. We report the immediate and early follow up of a group of consecutive adolescents and adults for whom stent angioplasty for CoA was the primary management strategy, including haemodynamic and angiographic assessment after implantation.

\section{Methods}

PATIENT POPULATION

Consecutive adult and adolescent patients ( $\mathrm{n}=27$, weight $>50 \mathrm{~kg}$ ) referred for management of CoA at either The Hospital for Sick Children or Toronto Congenital Cardiac Centre for Adults, Toronto, Canada, between November 1994 and September 1997 were offered and accepted participation in catheter directed management of their lesion. Because efficacy and safety issues have not been defined in terms of anatomy, no patient was excluded because of wall calcification, isthmal hypoplasia, CoA location (for example, near the left subclavian artery), or arch irregularity. Informed consent was obtained for all patients before the procedure. 


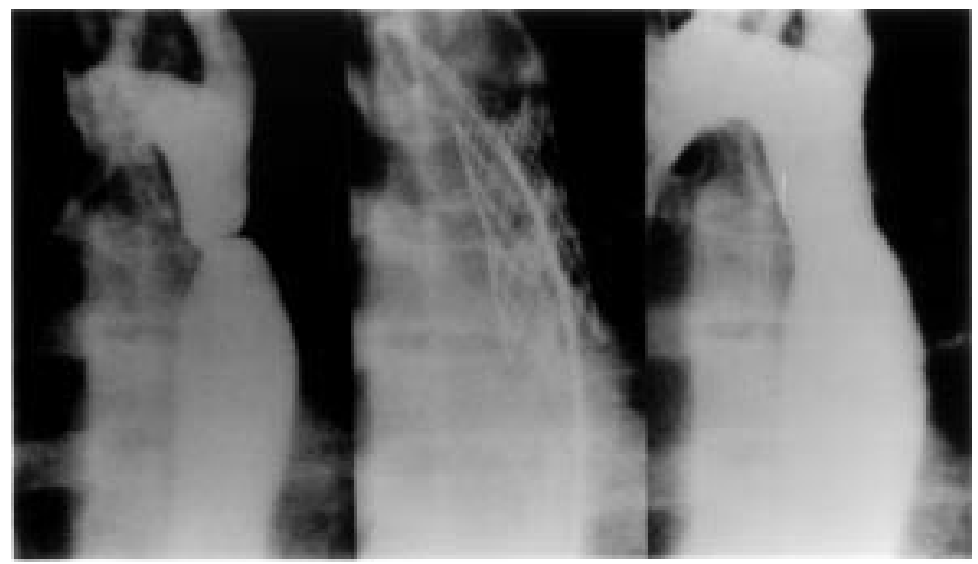

Figure 1 Aortograms from a coarctation of the aorta before (left panel) and after stent implantation (middle and right panel). All angiograms were taken in the left anterior oblique projection. discharge on the day following the procedure was planned for the majority of patients.

FOLLOW UP PROTOCOL

Patients were scheduled for clinical follow up at six weeks and one year after the procedure. If they were normotensive at the first follow up assessment, patients on antihypertension drugs were given a trial off treatment.

Patients ( $\mathrm{n}=18$ ) underwent a haemodynamic reassessment of the stent gradient and stent-CoA morphology one year after the procedure. Angiography was performed to assess the residual CoA diameter, the possibility of intimal hyperplasia, the presence of an aneurysm (defined as $>2 \mathrm{~mm}$ dyskinesis of the aortic wall), and the position of the stent relative to the aortic wall. Two investigators (LB, DH) measured aortic diameters off line.

\section{DATA ANALYSIS}

All measurements were calculated as mean (1 SD). Groups were compared by a Student's $t$ test (paired analysis where appropriate) with the level of significance set at 0.05 . Groups were also compared using $\chi^{2}$ or Wilcoxon rank-sum tests where appropriate.

\section{Results}

\section{POPULATION}

Twenty seven patients (15 male patients) underwent stent implantation for CoA. Mean age at procedure was 30.1(13.1) years (range 14-63 years). Seven patients had had previous surgery for CoA and balloon angioplasty had been performed in one patient. Hypertension was present in 26 patients, with a mean systemic blood pressure of 164 (26)/ $86(13) \mathrm{mm} \mathrm{Hg}$, and 16 patients were on antihypertension drugs. Seven patients were taking more than one drug; of the nine patients on monotherapy, five were on a $\beta$ blocker, three were on an angiotensin converting enzyme inhibitor, and one was on a calcium channel blocker. Cardiac surgery for problems other than CoA was required for four patients (aortic valve replacement in three, closure of ventricular septal defect in one). One patient presented with myocardial infarction at age 34 years and was scheduled for coronary artery bypass. CoA was managed with stent implantation before surgery at the request of the cardiac surgeon.

\section{PROCEDURE}

Baseline blood pressure proximal to the CoA was 149 (30)/80 (15) $\mathrm{mm} \mathrm{Hg}$ (mean 103 (18) $\mathrm{mm} \mathrm{Hg}$ ), and distal to the CoA was 102 (19)/75 (12) mm Hg (mean 84 (13) $\mathrm{mm} \mathrm{Hg}$ ) ( $\mathrm{p}=0.001$ systolic mean pressure difference). The mean peak gradient was 46 (20) $\mathrm{mm} \mathrm{Hg}$. CoA minimum diameter was 6.6 (3.6) $\mathrm{mm}$ (range $1-16 \mathrm{~mm}$ ). Of the two stent lengths available the $4 \mathrm{~cm}$ stent was placed in 15 patients and the $5 \mathrm{~cm}$ stent in the remainder. The CoA was dilated with a $15 \mathrm{~mm}$ diameter balloon in six patients, an $18 \mathrm{~mm}$ balloon in six patients (one pre-dilated with a $15 \mathrm{~mm}$ balloon), and a $20 \mathrm{~mm}$ balloon in 15 patients. In one case the CoA was immediately distal to the left subclavian artery and the stent was 
Table 1 Haemodynamic measurements: immediate results and at follow up

\begin{tabular}{|c|c|c|c|c|}
\hline & $\begin{array}{l}\text { Ascending aortic } \\
\text { pressure ( } \mathrm{mm} \mathrm{Hg} \text { ) }\end{array}$ & $\begin{array}{l}\text { Descending aortic } \\
\text { pressure (mm Hg) }\end{array}$ & $\begin{array}{l}\text { Mean pressure } \\
\text { ascending aorta } \\
\text { (mm Hg) }\end{array}$ & $\begin{array}{l}\text { Mean pressure } \\
\text { descending } \\
\text { aorta }(m m \mathrm{Hg})\end{array}$ \\
\hline Before procedure & $149(30) / 80(15)$ & $102(19) / 75(12)$ & $103(18)$ & $84(13)$ \\
\hline After procedure & $132\left(33^{\star}\right) / 80(19 \dagger)$ & $130\left(34^{\star \star \star \star}\right) / 80(19 \dagger)$ & $98(23 \dagger)$ & $97\left(24^{\star \star \star \star}\right)$ \\
\hline Follow up & $125\left(21^{\star \star \star}\right) / 75(11 \dagger)$ & $121\left(18^{\star \star \star \star \star}\right) / 73(12 \dagger)$ & $91\left(14^{\star \star}\right)$ & $89\left(14^{\star \star}\right)$ \\
\hline
\end{tabular}

intentionally placed across its origin without clinical effect to the patient. In another patient the catheter shifted position during balloon inflation, resulting in stent deployment distal to the CoA site, and was redilated within the descending aorta to stabilise its position. Two additional stents were then placed across the CoA site, one of which overlapped the origin of the left subclavian artery. One patient had minor distal migration of the stent during placement, although its final position adequately covered the CoA. No change in left arm pressure was noted in either patient. The final patient had recurrent CoA after a surgical coarctectomy. This patient had a substantially calcified scar at the restenosis site, which prevented initial low pressure dilation. A stent was placed during the first procedure with improvement in the gradient from $50 \mathrm{~mm} \mathrm{Hg}$ before to $20 \mathrm{~mm} \mathrm{Hg}$ after implantation. Unfortunately, after expansion of the balloon, and perhaps because of irregularities in the vessel wall, the balloon ruptured and required surgical removal. This patient returned for a second procedure in which a high pressure balloon was used. The gradient was $27 \mathrm{~mm} \mathrm{Hg}$ before the second procedure, $2 \mathrm{~mm} \mathrm{Hg}$ after the procedure, and $9 \mathrm{~mm} \mathrm{Hg}$ at follow up, although a small residual waist within the stent contour was still present.

Blood pressures immediately following implantation were 132 (33)/80 (19) $\mathrm{mm} \mathrm{Hg}$ (mean 98 (23) $\mathrm{mm} \mathrm{Hg}$ ) proximal and 130 (34)/80 (19) mm Hg (mean 97 (24) mm Hg) distal to the CoA (table 1). This was a slightly greater ascending systolic than descending systolic pressure $(\mathrm{p}=0.04)$, with no difference in ascending or descending mean pressures. The mean peak gradient was $3(5) \mathrm{mm} \mathrm{Hg}$, significantly less than before the procedure $(\mathrm{p}=0.001)$ (fig 2), and the minimum diameter within the stent increased to 16.9 (2.6) $\mathrm{mm}$ (range 9-20 mm, $\mathrm{p}=0.001$ ) (fig 3 ). The ratio of the CoA site to the transverse arch diameters rose from $0.35(0.2)$ (range $0.18-1.00, \mathrm{n}=25$ ) to $0.92(0.15)$ (range $0.62-1.13, \mathrm{n}=18$ ) $(\mathrm{p}<0.001)$.

\section{PROCEDURE COMPLICATIONS}

One patient with previous aortic valve replacement and prior coarctectomy had a right middle cerebral artery embolism immediately following the procedure, resulting in a minor residual neurological deficit complicated by seizures. In one patient the dilation balloon ruptured during stent inflation, described above. Other procedural issues with stent placement are commented on above.

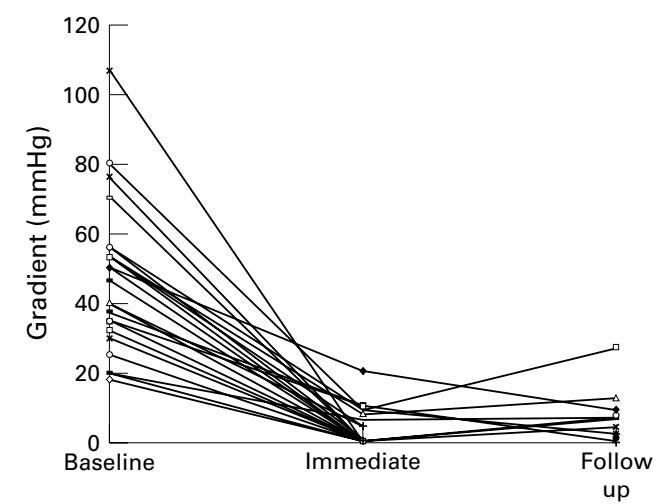

Figure 2 Pressure gradients at the coarctation of the aorta before, immediately after, and at follow up after stent implantation.

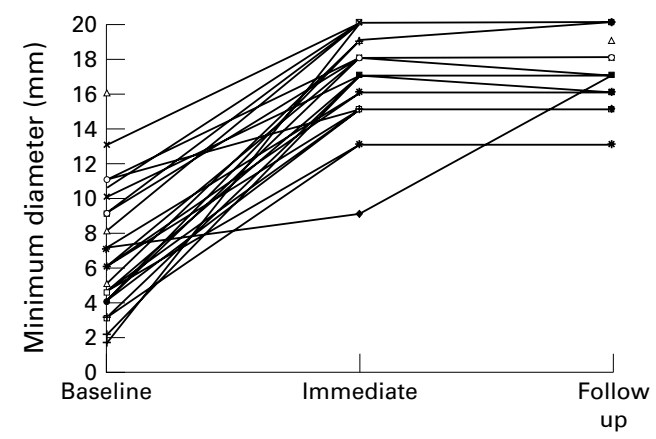

Figure 3 Minimum diameters at the coarctation of the aorta before, immediately after, and at follow up after stent implantation.

CLINICAL FOLLOW UP

One patient had coil embolisation for a persistent arterial duct at the time of stent implantation. Six months after stent insertion, a clinically important aneurysm $(>2 \mathrm{~cm})$ was noted associated with a residual gradient of $25 \mathrm{~mm} \mathrm{Hg}$. Angiographically, the stent had not fully expanded the associated hypoplastic isthmus. This patient's CoA was among the smallest, being $3 \mathrm{~mm}$ in diameter initially, and with the stent dilated to $15 \mathrm{~mm}$. Surgical removal of the stent with resection of the circumferential aneurysm and placement of an interposition graft were accomplished uneventfully.

The remaining 26 patients had clinical follow up at a mean of 1.8 (1.0) years (range $0.1-3$ years). Average blood pressure was 130 (14)/74 (11) $\mathrm{mm} \mathrm{Hg}$, and clinical gradient was 4 (8) $\mathrm{mm} \mathrm{Hg}$ (range $0-32 \mathrm{~mm} \mathrm{Hg}$ ). Seven patients were still receiving antihypertension treatment at their last assessment.

\section{HAEMODYNAMIC ASSESSMENT}

Follow up haemodynamic assessment was obtained in 18 of 26 patients 1.3 (0.5) years after the procedure. Blood pressure was 125 (21)/75 (11) $\mathrm{mm} \mathrm{Hg}$ (mean 91 (14) $\mathrm{mm} \mathrm{Hg}$ ) proximal and 121 (18)/73 (12) $\mathrm{mm} \mathrm{Hg}$ (mean $89(14) \mathrm{mm} \mathrm{Hg}$ ) distal to the stent (ascending systolic pressure greater than descending, $\mathrm{p}=0.02$, mean pressures not significantly different). The mean CoA gradient was 4 (6) $\mathrm{mm} \mathrm{Hg}$ (range $0-26 \mathrm{~mm} \mathrm{Hg}$ ) (fig 2).

Minimum stent diameter was $17.2(2.2) \mathrm{mm}$ (range 13-20 mm) (fig 3). Aneurysms were present at the CoA site in three patients, one of 


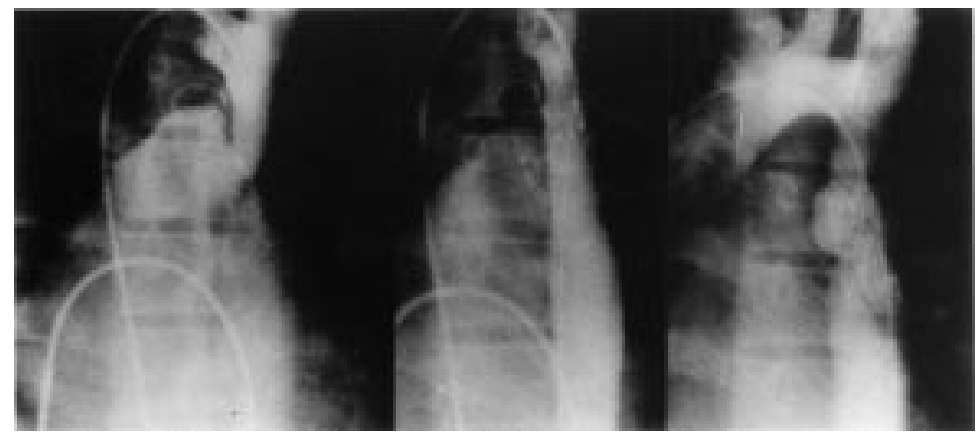

Figure 4 Left anterior oblique aortogram from the patient who developed a significant aneurysm requiring surgery, before (note filling of main pulmonary artery from a small arterial duct) (left) and after (middle) implantation. The right panel shows the appearance of the aneurysm noted angiographically at follow up (left anterior oblique projection).

whom required surgery (noted above); the others had areas of aortic wall dyskinesis and are under clinical follow up (fig 4). Thirteen of the 18 patients with angiographic follow up had minor intimal hyperplasia $(<1 \mathrm{~mm})$ without luminal compromise. Additionally, in 13 of the 18 patients the proximal, distal, or both ends of the stent were not in contact with the aortic wall. We have been unable to detect any consequence of stent non-adherence; specifically there have been no distal embolic events and no evidence for obstruction to flow through the stent struts.

The mean diameter of the transverse arch, the minimum stent diameter, and the descending aorta diameter were $21.4(2.8), 17.2(2.2)$ and $26.1(6.6) \mathrm{mm}$, respectively. The proximal mid and distal stent diameters were within $1 \mathrm{~mm}$ of each other. The mean transverse arch was $1.15(0.41)$ and the descending aorta 1.52 (0.35) times the minimum stent diameter. Of 16 patients for whom measurements of the descending aorta were available, three had a descending aorta more than double the size of the minimum stent diameter and four had a descending aorta between 1.5 and 2.0 times the minimum stent diameter.

MANAGEMENT OF PRIMARY COMPARED WITH RECURRENT COA

Seven of the 26 patients were managed for recurrent CoA after prior surgery. Blood pressure before angioplasty was similar in the two groups (surgical patients 166 (20)/83 (17) $\mathrm{mm} \mathrm{Hg} v$ non-surgical 164 (27)/87 (12) $\mathrm{mm} \mathrm{Hg}$ ), although there was a trend for more of the surgical patients to be on drugs (surgical $71 \%$ v non-surgical 55\%). Haemodynamic measurement before implantation revealed the surgical group to have a lower peak gradient (29 (12) mm Hg $v 51$ (20) $\mathrm{mm} \mathrm{Hg}$ in the non-surgical group, $\mathrm{p}=0.003$ ), the minimum obstructive diameter being larger for the surgical group $(9.9(2.2) \mathrm{mm} v 5.4$ (3.3) $\mathrm{mm}$, $\mathrm{p}=0.001)$. Immediately after implantation the gradient was the same in both groups (surgical 3.3 (8.2) $\mathrm{mm} \mathrm{Hg} v$ non-surgical 3.0 (4.1) $\mathrm{mm}$ $\mathrm{Hg}, \mathrm{p}=0.57)$ as was the minimum stent diameter (surgical 16.4 (3.8) $\mathrm{mm} v$ non-surgical $17.1(2.2) \mathrm{mm}, \mathrm{p}=0.91)$. Late haemodynamic follow up data were available for five surgical and 13 non-surgical patients. Gradient and minimal stent diameters remained similar for both groups (gradient 2.6 (4.0) $\mathrm{mm} \mathrm{Hg} v 5.2$ (7.3) $\mathrm{mm} \mathrm{Hg}, \mathrm{p}=0.50$; diameter 17.6 (2.3) $\mathrm{mm} v 17.1(2.3) \mathrm{mm}, \mathrm{p}=0.83$, in surgical and non-surgical patients, respectively).

\section{Discussion}

In the present study CoA balloon dilation with endovascular stent implantation resulted in a significant reduction in the CoA site gradient. At clinical follow up only seven of 26 patients were taking antihypertension drugs. The average blood pressure in all patients was 130 (14)/74 (11) mm Hg. Haemodynamic and angiographic assessment $1.3(0.5)$ years after the procedure showed a mean CoA gradient of only 4 (6) $\mathrm{mm} \mathrm{Hg}$; aneurysms were detected in three patients, one of whom required surgery. The other two had minor areas of dyskinesis in the aortic wall.

Previous studies of balloon angioplasty in adults consistently showed an improvement in the CoA gradient. ${ }^{13} 14171922{ }^{25}$ However, studies with more than 10 patients reported a residual mean gradient ranging from 8 (10) $\mathrm{mm} \mathrm{Hg}$ to 18 (15) $\mathrm{mm} \mathrm{Hg}$, and residual gradients of $>20 \mathrm{~mm} \mathrm{Hg}$ were found in $7 \%-26 \%$ of patients. At follow up, clinical hypertension or continued use of antihypertension drugs was reported in $27-68 \%$ of patients, and late haemodynamic restenosis (when reported) was found in $7-9 \% .^{13} 1417$ Other late complications were aneurysm formation in $7-15 \%$ and aortic dissection requiring urgent surgery in three patients. ${ }^{13} 1425$

To address these concerns, endovascular stents have been proposed as a potential technique to improve upon balloon angioplasty alone. As such, they have been applied in the setting of congenital heart disease for a number of indications including pulmonary arterial stenosis, and conduit and systemic venous obstructions with good sustained results. ${ }^{36}$ Previous evaluations of stent management of CoA have included case reports, ${ }^{29}{ }^{34}$ and small series $(\mathrm{n}<10)$ in which patients were often selected because their conditions were judged to be inappropriate for balloon angioplasty alone. These studies used smaller stents than were available for our study (often $3 \mathrm{~cm}$ length and over stretched diameter $18 \mathrm{~mm}$ ). Nevertheless, case series have reported encouraging results compared with those reported for angioplasty alone. For many patients, there was no residual gradient and mean residual gradients were 1 (1.6) $\mathrm{mm} \mathrm{Hg}{ }^{32} 2$ (3) $\mathrm{mm} \mathrm{Hg}^{28} 4$ (1) $\mathrm{mm} \mathrm{Hg}$, ${ }^{31}$ and 13.3 (23.2) $\mathrm{mm} \mathrm{Hg}^{30}$ in four studies. In three studies with clinical follow up and a combined population of 25 patients, five remained hypertensive at follow up. ${ }^{28}{ }^{30}{ }^{31}$ Uniquely in our study, our population comprised consecutive patients presenting for management of CoA, all of whom were scheduled for clinical follow up and the majority of whom agreed to haemodynamic re-evaluation. It is important that the stent device inserted was substantially larger and longer (maximal rated diameter) than those used by others and that the majority of patients were adults.

Excellent immediate haemodynamic results were obtained in this study, with a reduction in 
CoA gradient to 3 (5) $\mathrm{mm} \mathrm{Hg}$ and only one of 26 patients with a residual gradient of $20 \mathrm{~mm} \mathrm{Hg}$. Further, haemodynamic reassessment in 18 patients showed that the CoA site gradients remained low (mean $4(6) \mathrm{mm} \mathrm{Hg}$ ) with persistent but dilatable stenosis documented in only one of these patients. Persistent hypertension at clinical follow up was present in seven of 26 patients, less than has been reported for angioplasty alone. ${ }^{1314} 17192225$ Aneurysms remain a potential issue of concern and were found in three of 18 patients studied, one of whom required surgery. The morphology of the lesion and potential for aneurysm development in this latter patient deserves further comment. In a subset of patients with $\mathrm{CoA}$ (as in this patient), the obstructive element is an invagination of the wall of the vessel (fig 4) rather than an endoluminal shelf. Therefore, there is little or no vessel circumference for either dilation or stenting. These patients should undergo either serial progressive stent enlargement or primary referral to surgery. Discordant motion during the cardiac cycle between the ascending and descending aorta, seen angiographically, is the clue to this anatomical situation. Alternatively, application of intravascular ultrasound may define this higher risk subgroup, by defining the margins of the aortic wall. In this regard, intravascular ultrasound may also be of value in addressing additional issues such as the potential (although not observed in this study) for stent thrombus formation, particularly between stent struts that are not opposed to vessel wall.

The mechanism of minor wall irregularities, which may lead to clinically significant aneurysms, may be tears in the thin non-fibrous shelf region of the vessel wall. As the stent struts maintain an enlarged circumference with exposure of the thinned wall to arterial pressure, a wall irregularity beyond the limits of the stent may develop. Taking care in not overdistending the vessel - that is, stent dilation of the fibrous shelf to the limits of normal aortic wall - and the possibility of staged, sequential dilations over a period of several months may avoid this problem. Further studies are required to address these approaches. Anatomical proximity of the CoA to the left subclavian artery makes stent placement near or up to the ostium unavoidable. Angiographic and haemodynamic observations in instances where placement was close to or impinging upon the left subclavian ostium revealed no evidence of flow compromise. That this is not a surprise rests with the unobstructive character of flow through the stent struts.

Angiographic follow up has shown minor intimal hyperplasia in a majority of patients (13 of 18 in the present series). At present this does not have a haemodynamic effect and we believe that the intima is unlikely to proliferate to an extent that would cause obstruction in the future. That this may be the case is not surprising, given the high flow through the region and the large diameter achieved. ${ }^{36}$ This possibility will need to be re-evaluated over a longer follow up time. Proximal or distal stent nonadherence to the aortic wall was observed in 13 of the 18 patients who were re-evaluated angiographically. The significance of this observation is uncertain because no clinical consequence has been detected. Our observations did not define any anatomical subgroup in whom stenting was technically unachievable or not acutely effective. The noted procedural complications are avoidable with experience. Whether patients with CoA in the absence of an obstructing shelf should have sequential stent expansion or should not have the procedure at all has not been determined.

There are potential problems in the long term follow up of endovascular stents, which were not observed in this study. Specifically, there is the possibility of stent migration into the descending aorta, although because no migration was detected in the first year we think that this will be unlikely. Metal fatigue has not been observed because the implants were expanded well within their rated diameters. If metal fatigue were to occur, it may not result in an embolic complication because the majority of the stent is covered with endothelium. The possibility for device erosion is not known.

\section{LIMITATIONS}

Although this is the largest reported group of patients managed with stent implantation for CoA, this study was limited by the relatively small number of patients, making accurate evaluation for risk difficult and infrequent complications less likely to be observed. Similarly, the follow up time was short in relation to the patients' expected lifespan, thus preventing observation of late complications, which may have important future consequences. There were two major limitations to the study design. Firstly, we did not compare the study population with a surgical cohort. A randomised comparison with surgical patients would be the optimal assessment but would require multicentre involvement to accomplish within a meaningful time. Such a study would be limited to centres that can offer expertise in both techniques. Secondly, we did not perform an exercise test evaluation during follow up. Exercise induced hypertension is frequently observed, with uncertain clinical significance. It would be of interest in the future to compare the effectiveness of stent techniques with surgical techniques in preventing exercise induced hypertension.

\section{CONCLUSION}

In summary we have shown that stent implantation as primary management for CoA is an effective intervention for gradient reduction with acceptable procedural risk. Application of this technique has significantly improved upon the problem of restenosis observed following angioplasty alone. The possibility for late complications has not yet been evaluated but is expected to be low. The noted alterations in wall configurations (small aneurysms) require careful observation to determine their static or progressive nature. We believe that stent implantation can be recommended as an acceptable alternative to surgery for CoA. 
1 Bobby JJ, Emami JM, Farmer RDT, et al. Operative survival and 40 year follow up of surgical repair of aortic

2 Malan JE, Benatar A, Levin SE. Long-term follow-up of coarctation of the aorta repaired by patch angioplasty. Int $f$ Cardiol 1991;30:23-32.

3 Kappetein PA, Guit GL, Bogers JJC, et al. Noninvasive long-term follow-up after coarctation repair. Ann Thorac Surg 1993;55:1153-9.

4 Stewart AB, Ahmed R, Travill CM, et al. Coarctation of the aorta life and health $20-44$ years after surgical repair. $B r$ Heart F 1993;69:65-70.

5 Kimball TR, Reynolds JM, Mays WA, et al. Persistent hyperdynamic cardiovascular state at rest and during exercise in children after successful repair of coarctation of the aorta. 7 Am Coll Cardiol 1994;24:194-200.

6 Zehr KJ, Gillinov AM, Redmond JM, et al. Repair of coarctation of the aorta in neonates and infants: a thirty-year tation of the aorta in neonates and infants:

7 Lababidi ZA, Daskalopoulos DA, Stoeckle H. Transluminal balloon coarctation angioplasty: experience with 27 patients. Am 7 Cardiol 1984;54:1288-91.

8 Beekman RH, Rocchini AP, Dick M, et al. Percutaneous balloon angioplasty for native coarctation of the aorta. $\mathcal{F}$ Am Coll Cardiol 1987;10:1078-84.

9 Cooper RS, Ritter SB, Rothe WB, et al. Angioplasty for coarctation of the aorta: long-term results. Circulation 1987;75:600-4

10 Wren C, Peart I, Bain H, et al. Balloon dilation of unoperated aortic coarctation: immediate results and one year follow-up. Br Heart f 1987;58:369-73.

11 Morrow WR, Vick GW, Nihill MR, et al. Balloon dilation of unoperated coarctation of the aorta: short- and intermediate-term results. f Am Coll Cardiol 1988;11:133 8.

12 Tynan M, Finley JP, Fontes V, et al. Balloon angioplasty for the treatment of native coarctation: results of valvuloplasty and angioplasty of congenital anomalies registry [see comments]. Am 7 Cardiol 1990;65:790-2.

13 Fawzy ME Dunn B, Galal O, et al. Balloon coarctation angioplasty in adolescents and adults: early and intermediangioplasty in adolescents and adults: early

14 Tyagi S, Arora R, Kaul UA, et al. Balloon angioplasty of native coarctation of the aorta in adolescents and young adults. Am Heart f 1992;123:674-80.

15 Fletcher SE, Nihill MR, Grifka RG, et al. Balloon angioplasty of native coarctation of the aorta: midterm follow-up and prognostic factors. I Am Coll Cardio 1995;25:730-4.

16 Ovaert C, Benson LN, Nykanen D, et al. Transcatheter treatment of coarctation of the aorta: a review. Pediatr Cardiol 1998;19:27-44.

17 Fawzy ME, Sivanandam V, Galal O, et al. One- to ten-year follow-up results of balloon angioplasty of native coarctation of the aorta in adolescents and adults. $\mathcal{F} \mathrm{Am}$ Coll Cardiol 1997;30:1542-6.

18 Schrader R, Bussmann WD, Jacobi V, et al. Long-term effects of balloon coarctation angioplasty on arterial blood pressure in adolescent and adult patients. Cathet Cardiovasc piagn 1995;36:220-5.
19 Phadke K, Dyet JF, Aber CP, et al. Balloon angioplasty of adult aortic coarctation. Br Heart f 1993;69:36-40.

20 Kulick DL, Kotlewski A, Hurvitz RJ, et al. Aortic rupture following percutaneous catheter balloon coarctoplasty in an adult. Am Heart f 1990;119:190-3.

21 Rico J, Sobrino N, Calvo L, et al. Angioplastia translumina percutanea en la coartacion aortica del adulto joven. Rev Esp Cardiol 1989;42:415-7.

22 Attia IM, Lababidi ZA. Early results of balloon angioplasty of native aortic coarctation in young adults. $\mathrm{Am} \mathcal{F}$ Cardiol 1988;61:930-1.

23 Biswas PK, Mitra K, De S, et al. Follow-up results of balloon angioplasty for native coarctation of aorta. Indian Heart $\mathcal{F}$ 1996;48:673-6.

24 Kale PA, Lokhandwala YY, Kulkarni HL, et al. Balloon angioplasty for native aortic coarctation. Indian Heart $\mathcal{f}$ 1992;44:207-11

25 Ray DG, Subramanyan R, Titus T, et al. Balloon angioplasty for native coarctation of the aorta in children and adults: factors determining the outcome. Int 7 Cardiol 1992;36: 273-81.

26 Suarez de Lezo J, Sancho M, Pan M, et al. Angioplasty follow-up after balloon angioplasty for coarctation of the aorta. F Am Coll Cardiol 1989;13:689-95.

27 Syamasundar P, Thapar MK, Kutayli F, et al. Causes of recoarctation after balloon angioplasty of unoperated aortic coarctation. 7 Am Coll Cardiol 1989;13:109-15.

28 Suarez de Lezo J, Pan M, Romero M, et al. Balloonexpandable stent repair of severe coarctation of aorta. $\mathrm{Am}$ Heart f 1995:129:1002-8.

29 Rosenthal E, Qureshi SA, Tynan M. Stent implantation for aortic recoarctation. Am Heart f 1995;129:1220-1.

30 Bulbul ZR, Bruckheimer E, Love JC, et al. Implantation of balloon-expndable stents for coarctation of the aorta: implantation data and short-term results. Cathet Cardiovasc Diagn 1996;39:36-42.

31 Ebeid MR, Prieto LR, Latson LA. Use of balloonexpandable stents for coarctation of the aorta: initial results and intermediate- term follow-up. $\mathcal{F}$ Am Coll Cardiol 1997; 30:1847-52.

32 Ledesma M, Diaz y Diaz E, Alva Espinosa C, et al. Stents en coartacion aortica. Resultados inmediatos. Arch Inst Cardiol Mex 1997;67:399-404.

33 Pedulla DM, Grifka RG, Mullins CE, et al. Endovacular stent implantation for severe recoarctation of the aorta: case report with angiographic and 18-month clinical case report with angiographic and 18-month

34 Diethrich EB, Heuser RR, Cardenas JR, et al. Endovascular techniques in adult aortic coarctation: the use of stents for native and recurrent coarctation repair. 7 Endovasc Surg 1995;2:183-8.

35 Magee AG, Brzezinska-Rajszys G, Qureshi SA, et al. Stent implantation for aortic coarctation and recoarctation. Heart 1999;82:600-6.

36 O'Laughlin MP, Slack MC, Grifka RG, et al. Implantation and intermediate-term follow-up of stents in congenital heart disease. Circulation 1993;88:605-14.

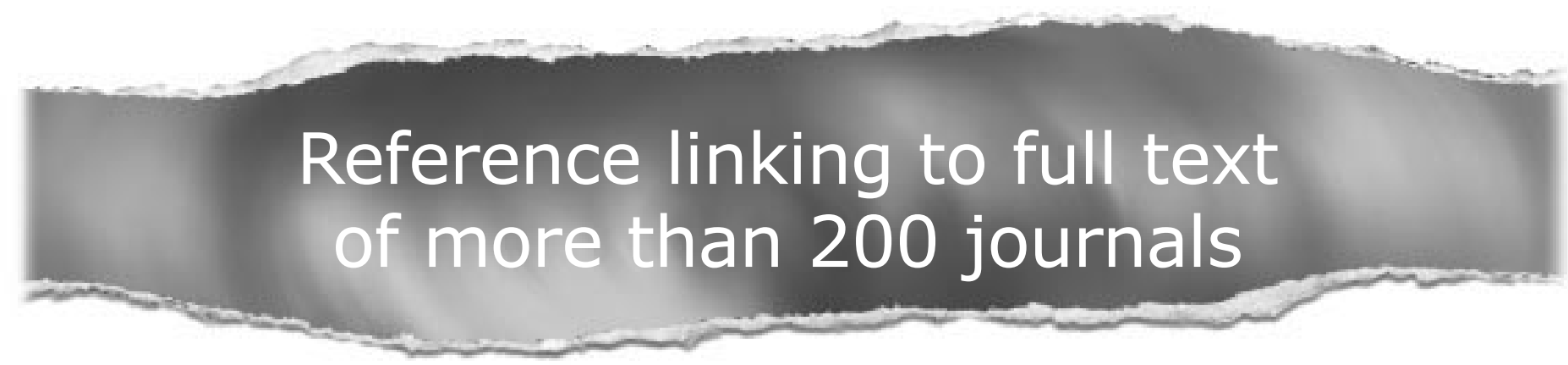

Toll free links

You can access the FULL TEXT of articles cited in Heart online if the citation is to one of the more than 200 journals hosted by HighWire (http://highwire.stanford.edu) without a subscription to that journal. There are also direct links from references to the Medline abstract for other titles.

\section{www.heartjnl.com}

